\title{
Age 5 Cognitive Development in England
}

\author{
Kirstine Hansen ${ }^{1}$ and Elizabeth M. Jones ${ }^{2}$ \\ Centre for Longitudinal Studies, Institute of Education, University of London
}

Draft October 2009

${ }^{1}$ Corresponding author. Present address: Centre for Longitudinal Studies, Institute of Education, 20 Bedford Way, London, WC1H 0AL. E-mail: khansen@ioe.ac.uk. Tel: +442076126997.

${ }^{2}$ Present address: Centre for Longitudinal Studies, Institute of Education, 20 Bedford Way, London, WC1H 0AL. E-mail: e.jones@ioe.ac.uk. Tel: +442079115566. 


\begin{abstract}
Children's development in the early years has been shown to be related to their success in later life in a range of areas including education, employment and crime. Determining why some children do better than others in the early years is a key issue for policy and is crucial in attempts to reduce inequalities. This research examines differences in early child development by examining the factors associated with the cognitive ability of children up to age 5 using cognitive assessments administered as part of the Millennium Cohort Study (MCS) and teacher reports of child ability. The results show that younger children, those with low birth weight, lower parental education, lower income and living in social housing is related both to lower achievement, on average. and the probability of being at the bottom of the distribution of cognitive scores at age 5.
\end{abstract}




\section{Introduction}

Children's development in the early years has been shown to be related to their success in later life in a range of areas including education, employment, crime and early parenthood.

Determining why some children do better than others in the early years is a key issue for policy and is crucial in attempts to reduce inequalities. Such thinking lies behind a number of key policy initiatives such as Every Child Matters in the UK and No Child Left Behind in the US. These policies seek to ensure that all children, no matter their background or circumstances, are able to realize their potential and enjoy and achieve in life.

This research examines differences in early child development by examining the factors associated with the cognitive ability of children up to age 5 in the Millennium Cohort Study (MCS). The paper focuses on two aspects of cognitive development at age 5 . The first part examines the factors associated with achievement in survey-administered tests and teacherassessed performance at age 5. These results will tell us about the factors that are, on average, associated with increased or decreased achievement at age 5. However, social scientists and policy makers are also likely to be concerned with the factors related to a child being at the bottom of the achievement distribution. Indeed, to ensure that 'no child is left behind' one could argue that policy needs to target children at the bottom, particularly if resources are scarce. For this reason the second part of the paper focuses on children at the bottom of the achievement distribution.

\section{Background}

Assessment results from early in life are related to outcomes much later, throughout school and into adulthood. Cognitive assessment scores from before or upon school entry are related to academic outcomes throughout schooling. A study using data from six different longitudinal studies from the United States, Canada and United Kingdom found that school-entry assessments of mathematics, reading and attention skills were associated with later school 
achievement at ages ranging from 8 years to 14 years. This relationship was seen even when a variety of background family factors were controlled for. School-entry mathematics assessments were found to be the strongest predictor, followed by reading scores, then attention skills (Duncan et al. 2007).

Early childhood assessments are also related to adult academic attainment and occupational outcomes. Scores on an intelligence test between ages 3 and 5 were related to chances of being unemployed in young adulthood in a longitudinal study of New Zealanders (Caspi et al., 1998). Moreover, being in the bottom quartile of cognitive assessment scores at age 5 was related to higher odds of having low income, having low qualifications and experiencing worklessness at age 30 in the 1970 British Cohort Study (BCS70; Feinstein and Bynner, 2004).

Feinstein and Duckworth (2006), using the BCS70, found that a copying designs test given at age 5 was highly related to academic assessments at age 10 and educational attainment and income at age 30. This relationship was seen even when a variety of family and child variables, previous development, and maternal attitude were controlled for in the analyses.

While it is informative to know that cognitive indicators quite early in life predict later outcomes, this is of little policy use without an understanding of what factors are associated with these early indicators or what factors have the potential to affect or interrupt the relationship between them and later outcomes. This information would allow for either improvement of early indicators or interventions to allow positive adult outcomes despite poorer cognitive indicators in childhood. Schoon et al. (2002), in a study using data from the National Child Development Study (NCDS) and the BCS70, found that persistent disadvantage was more of a risk to later outcomes than was only early disadvantage, suggesting that alleviating disadvantage during childhood could have beneficial effects on adult outcomes.

Although early academic and cognitive assessments are good predictors of later outcomes, a number of other factors are related both to the early assessment results and to 
trajectories over time. A major factor in academic achievement and attainment is parental education. Hansen and Hawkes (2009) and Hansen et al. (2009) show that of all the factors related to early child outcomes measured in the MCS, maternal education is of key importance. Blanden et al. (2005), using data from the NCDS and BCS70, show that education plays a major role in the intergenerational transmission of advantage or disadvantage across generations.

Parental income and social class are also strongly associated with the intergenerational transmission of advantage or disadvantage (Blanden and Machin 2007; Blanden et al. 2007; Blanden and Gregg 2004; Goldthorpe 1992; Goldthorpe and Erikson 2002). Children who live in households with lower incomes have been found to have lower test scores in the MCS than other children (Ermisch 2008; Hansen and Hawkes 2009; Hansen et al. 2009). Feinstein (2003), using the BCS70, found that children from lower SES families tended to get lower cognitive scores in the subsample assessed at 22 months than did children from higher SES families. It is likely that both income and social class are related to children's cognitive development through a variety of family and environmental factors, which are not detailed here but include more exposure to stressors, lower levels of cognitive stimulation at home and a greater likelihood of attending poor schools (Linver et al. 2002; McLoyd 1998).

Pre-school academic and cognitive assessment scores also differ among ethnic groups, but the size of the difference varies with age. In a study of students in a US city school district, Alexander et al. (1988) found that black and white children did not differ significantly on an achievement test at the start of school, but by the end of the first year the black students had lower scores than the white students and this gap grew in the second year of school. A more recent study using longitudinal data from the US found a black-white test score gap at the start of school, but this difference disappeared once covariates were entered into the analyses (Fryer and Levitt 2004, 2006). Brooks-Gunn et al. (1996), also using US data, found that controlling for social and economic differences across ethnic groups all but eliminated differences in test 
scores between black and white children. Biedinger (2010), in a study of pre-school children in

Germany, found that children of Turkish background scored lower than children of German

background on an assessment of cognitive development. This difference was reduced by

adding social background into the model and was no longer statistically significant once parental

activities with the child were also added. In the UK, MCS analysis has produced a similar

picture - at age 3 considerable differences exist in the scores of children from different ethnic

groups, with white children achieving the highest scores and Pakistani and Bangladeshi children

performing particularly poorly (George et al. 2007). By age 5 this gap is reduced and mostly

eliminated once other background factors are taken into account (Hansen and Hawkes 2009;

Hansen et al. 2009).

\section{Data}

The data used in this analysis are from the MCS, which is a longitudinal survey of around 19,000 children born in the UK over a 12 month period and living in selected electoral wards at age 9 months. The analysis uses data for England only ${ }^{3}$ from the first 3 sweeps of the MCS, which provide information on children and their families at approximately 9 months (MCS 1), 3 years (MCS 2$)$, and 5 years of age (MCS 3$){ }^{4}$

\section{The sample}

\footnotetext{
${ }^{3}$ The sample is limited to families in England because one of the outcome variables-the Foundation Stage Profile (FSP) — is available only for children in England. Children in Wales, Scotland, and Northern Ireland were also rated by teachers using a similar instrument, but the results are not directly comparable to the FSP.

${ }^{4}$ The MCS sample was taken from the UK population which was stratified by country: England, Wales, Scotland, and Northern Ireland. England was stratified into three types of ward: ethnic minority, in which at least 30 per cent of the residents were ethnic minorities; disadvantaged, which were those that were in the 25 per cent poorest wards; and advantaged, which is a relative label for those wards not falling into either of the other two categories. Wards in Wales, Scotland, and Northern Ireland were stratified into advantaged and disadvantaged. All children born in the selected wards between the specified dates (approximately a year starting in mid to late 2000), who were eligible for child benefits and were alive and living in the UK at age nine months were part of the preliminary MCS sample. Full details of the sampling are available in the technical report on sampling (Plewis 2007).
} 
There were 9,717 families in England interviewed at the third sweep of the MCS. For the analyses, only those families who participated in all 3 sweeps are included, which reduces the sample to 8,314 families. Dropping main respondents who are not the cohort child's mother brings the sample down to 8,131 families. We selected only singleton births and one child from each twin or triplet family, giving us one cohort member child per family in the analyses. However, not all of these children have valid data for the cognitive outcomes examined in this paper. Selecting only those who do means the final sample numbers vary by outcome examined.

\section{Child outcomes at age 5}

Cognitive abilities at age five were measured in the MCS using three subscales of the British Ability Scales Second Edition (BAS II). These are Naming Vocabulary, Picture Similarities and Pattern Construction. The three subscales capture core aspects of verbal, pictorial reasoning and spatial abilities (Elliott, 1996; Hill, 2005). The vocabulary test is a test where children are shown pictures of objects and asked to identify them. Pictorial reasoning asks children to identify pictures similar to the ones shown to them. The spatial abilities test requires children to reproduce patterns shown to them in a book and by the interviewer out of coloured blocks. The assessments were administered using Computer Assisted Personal Interviewing (CAPI) by interviewers who were specially trained, but were not professional psychologists.

These survey-administered tests are considered together in this paper. A principal components analysis (PCA) was run on the BAS subscales. The first component accounted for 56 per cent of the variance. The loadings on the first factor were .57 for picture similarities, .57 for naming vocabulary, and .59 for pattern construction. The factor score was saved as the overall BAS score.

In addition to the assessments administered as part of the survey, Foundation Stage Profile (FSP) scores were collected by the Department for Children, Schools, and Families 
(DCSF) for cohort members in state schools in England and linked to the survey data. The FSP scores are teacher-reported achievement recorded at the end of the first year of school. The score used in this paper sums six areas of learning: 1) personal, social and emotional development; 2) communication, language and literacy; 3) mathematical development; 4) knowledge and understanding of the world; 5) physical development; and 6) creative development.

This paper examines two aspects of achievement at age 5. The first part examines which factors are associated with the survey-administered tests and teacher assessments at age 5 in general, while the second focuses on the factors related to the probability that a child scores in the bottom 30 per cent of the achievement distribution in these tests. The paper deals with each in turn.

\section{Descriptive Statistics}

Descriptive statistics on the age 5 outcomes are presented in Table 1, which shows the unweighted sample size, the mean scores, the standard deviation, the minimum and maximum score achieved in each assessment within our sample and the scores at various points of the weighted distribution.

The BAS overall scores (from the principal components analysis) ranged from 23.8 to 156.6 with a mean of 101.5 and standard deviation of 14.1. The scores on the Foundation Stage Profile ranged from 0 to 117 with a mean of 86.8 and standard deviation of 18.6 .

\section{Analysis and modelling}

Having charted the basic descriptive details of the outcomes, we now turn to assessing differences in achievement by various characteristics of children and their families to gain some insight into the variation of scores at age 5 . To do this we use regression analysis which allows 
us to look at the relationship between outcomes and a number of factors which theory and past empirical work inform us maybe related to achievement.

There are a number of advantages of using longitudinal data, such as the MCS, to do this type of analysis. Firstly, they are rich in background information, providing data not only on the cohort members themselves, but also the families and the environments in which the children grow up. Secondly, because they follow the same people over time, this allows us to model outcomes at later periods than the inputs.

The analysis is based on a model that maps child outputs to inputs and where child outcomes depend not only on child characteristics but also other family characteristics. The outcomes are the BAS or FSP scores for the child, which have been transformed into Z scores across our sample. This means that the coefficients can be interpreted as standard deviation differences. The right hand side of the model includes a set of independent variables which examine the child's characteristics (age at test, birth weight, birth order and gender); a set of family characteristics (ethnicity of the mother, highest parental qualification, maternal depression any time up to MCS 2, family income (averaged over MCS 1 and MCS 2), whether the mother was a lone parent at any time up to MCS 2, whether any parent was in a professional or managerial position at MCS 2; and whether the family lived in social housing (up to MCS 2)); and a set of parental decision variables (reading, teaching the alphabet and counting with the child at MCS 2; children's television watching at MCS 2; and whether the child has received any formal childcare up to and including age 3). A final set of value-added variables are added to the model capturing achievement at age 3, measured by performance in BAS and Bracken School Readiness Tests, and problem behavior as measured by the Strengths and Difficulties Questionnaire at age 3 (see Hansen and Hawkes, 2009 for further details). These scores are also likely to be related to our independent variables. If the coefficients on these variables are statistically non-significant in the model that controls for other independent variables, ability at age 3 exerts no independent influence on outcomes at age 5 . If 
their inclusion in the model reduces other independent variables to statistical insignificance, then those other variables are associated with cognition at age 3 but not with additional cognitive performance from 3 to $5^{5}$

As the outcome measures are essentially continuous we run ordinary least squares regressions using 'survey' commands in STATA. The 'survey' commands have to be used because the data are clustered by ward. This clustering needs to be taken account of in the statistical analysis to ensure corrected standard errors and valid significance tests of the estimates are reported. There are a number of ways to do this, as reported in Hansen and Hawkes (2009): 1) use survey commands; 2) use clustered robust standard errors in standard analysis; or 3) use a multi-level (hierarchical) model. Due to the fact that in the MCS the correlation is produced as a direct result of the survey design the most appropriate method of dealing with the data is to use survey commands to run analyses (STATA library ${ }^{6}$ ).

While our models endeavor to control for the factors identified in previous research as associated with child cognitive outcomes we cannot determine that these relationships are necessarily causal. In addition, there are likely to be factors that are related to the outcomes that our models are unable to capture either because we do not have an accurate measure of them or because they are unobservable. For example, there is likely to be a genetic component to a child's ability in a similar way there is to children's physical features. However, our analysis is unable to say anything about how important this component is or how it interacts with the factors included in our models.

\section{Results}

\footnotetext{
${ }^{5}$ The correlations of the MCS 2 value-added variables with the MCS 3 outcome variables range in magnitude from 0.23 to 0.45 .

${ }^{6}$ https://www.ats.ucla.edu/stat/stata/library/cpsu.htm
} 
Each set of independent variables are entered into the model alone, then together in a full model. A value-added model makes a fifth and final model specification. The results of these ordinary least squares regressions are shown in Tables 2 and 3 . The first column (1) is a regression of the outcome scores on child characteristics. The second column (2) focuses on family characteristics; the third (3) examines parental decisions; the fourth (4) controls for all the variables together; while the fifth (5) is the value added model which adds to the full model controls for achievement at age 3.

This value-added model tries to control for the child's ability. If it does so successfully it is the preferred model as it controls for all factors together, allowing us to compare which of the factors are most associated with the outcomes. However, we need to bear in mind that it measures ability at age 3 by using survey-administered tests, performance in which is likely to be associated with similar factors associated with age 5 achievement. In this case it may be that previous achievement has no individual association with cognition at age 5 other than through background variables which are associated with prior achievement. On the other hand, it may be that background variables are associated with cognition at age 3 but not at age 5 once previous achievement is added to the model.

Table 2 shows the results for the aggregated survey-administered BAS test scores and Table 3 the Foundation Stage Profile scores. As the outcomes have been transformed into Z scores the coefficients can be interpreted as standard deviation differences. If the coefficients on any of the control variables remain significant in the final models then these factors are either positively or negatively associated with that particular outcome even after controlling for other factors which may influence the relationship.

\section{BAS survey tests}

Table 2 shows that all child characteristics are associated with the survey test scoresolder children, girls, children with higher birthweight and first-born children have higher test scores. Of the family characteristics higher parental qualifications, higher family income, and 
having a parent in a professional or managerial occupation are all related to higher test scores. Living in social housing is related to lower test scores, as is having a non-white mother or a mother who has been diagnosed as depressed.

In the parental decision model (column 3), all but being taught counting are related to test scores. Having experience of formal childcare, up to and including age 3 , and being read to and taught the alphabet at MCS 2 are related to higher test scores. Watching three or more hours of television per day on the other hand is related to lower test scores.

In the full model, apart from television watching, the variables in the first two models remain significantly associated with the aggregated BAS survey test scores at age 5 , though their magnitudes are slightly reduced.

When we look at the value-added model, which controls for development reached at age 3 , there is general attenuation of all previous coefficients. The relationship of mother's ethnicity to test scores remains significant only for children with Pakistani and Bangladeshi mothers or mothers of mixed ethnicity. Many associations remain significant in this model also: age; birth weight; and having a parent with 5 GCSEs grade A-C, with A-levels or with a degree . Family income also remains significant after controlling for achievement at age 3 , with a $£ 100$ per month higher family income associated with a .051 standard deviation higher BAS score. Having at least 1 professional parent is associated with higher test scores. Teaching the alphabet to a child every day is also positively associated with BAS scores in this model.

The coefficients on the age 3 cognitive tests are significant—children with better scores on the BAS vocabulary test and the Bracken School Readiness assessment at age 3 score higher on the aggregated BAS survey test scores at age 5 . Those with more problem behaviour at age 3 have lower test scores at age 5 .

How do the standard deviation differences relate to BAS scores?

We know from the results which characteristics are associated with differences in BAS scores and by how many standard deviations. We also know from Table 1 that for BAS a 
standard deviation is 14.08 . This means that we can work out the differences in BAS scores for children with a given set of characteristics. So for example, a child who has at least 1 parent with 5 or more A-C passes at GCSE level achieves, on average, 2 more marks than a child with the same characteristics but whose parents do not have 5 A-C passes at GCSE $(.121 * 14.08)$. The gap in scores is roughly the same for children with a parent educated to A-level versus no GCSEs. If a parent has a degree then a child, on average, scores an additional point compared to children with an A-level or GCSE educated parent and 3 points more than a child whose parents do not have 5 A-C passes at GCSE level.

Having a family income of $£ 250$ per month higher is associated with an increase in a child's BAS score of 1.5 points. This means a child with a monthly family income of $£ 3000$ (roughly $£ 50,000$ per year) is associated with a BAS score 10.5 points higher than a child with a family income of $£ 1500$ per month. Having at least 1 parent in a professional or managerial position means that a child will score 1 more point on BAS than a child whose parents are not professionals or managers. On the other hand, children whose mothers are Pakistani, Bangladeshi or of mixed ethnicity score 3 points lower than a child with similar characteristics but whose mother is white.

However, children are likely to have a range of factors which affect their score rather than just one. These will cumulate to produce larger differences in BAS scores. For example, a white child with at least 1 parent educated to degree level and at least 1 parent in a professional or managerial position, with a family income $£ 250$ per month higher will, on average, score 8.5 points more on the BAS tests than a child whose mother is Pakistani, Bangladeshi or of mixed ethnicity, whose parents do not have 5 GCSE passes at grade A-C and are not in a professional or managerial position, earning $£ 250$ per month less. This is likely to be a conservative estimate as the income gap between families with these characteristics is likely to be considerably greater than £250 per month. 
Given that only 10 points separate a score at the $25^{\text {th }}$ percentile of the BAS distribution and a score at the $50^{\text {th }}$ percentile, or the $50^{\text {th }}$ compared to the $75^{\text {th }}$ percentile (Table 1 ) even our conservative 8.5 point gap estimate will greatly affect a child's placing on the ability distribution.

\section{The Foundation Stage Profile scores}

The scores considered to date are those administered as part of the MCS survey. However, we also have the teacher assessments of the child during the first year of school in the FSP scores. The FSP differs from the BAS in that the former is a teacher rating of children's performance based on teachers' assessments of students over an entire school year. While both should be capturing children's ability they will do so differently and may therefore be differentially associated with the independent variables examined. The FSP may be affected by teachers' perceptions of the children in general (e.g., their behaviour in class) which may affect how a teacher rates a child's ability.

As the FSP and BAS assess children's ability in different ways and the correlation between them is not particularly high (.44) we may expect to find that they are associated with slightly different factors. However, examination of Table 3 shows that this appears not to be the case; the variables associated with the FSP scores are, to a large extent, those we have already seen associated with the survey-administered BAS outcome.

All of the child characteristics (column 1) are statistically significantly related to FSP scores. Older children, girls, children with heavier birth weights and first born children have higher FSP scores.

Most of the family characteristics (2) are related to FSP scores. Children of Indian, Bangladeshi, or Pakistani mothers have lower FSP scores, on average, than children with white mothers. Parental qualifications, family income and parental professional or managerial occupation status are positively related to FSP scores. Maternal depression, lone parenthood and living in social housing are related to lower FSP scores. 
In the parental choice model (3), children who received formal childcare, were read to every day and were taught the alphabet every day had higher test scores on average. On the other hand, children who watched more than three hours of television per day had lower scores than other children.

In the full model (4), most of the relationships remain, but the coefficients on being first born, having an Indian mother, having a lone parent and television watching are reduced to statistical insignificance.

All of the age 3 measures are statistically significantly related to age $5 \mathrm{FSP}$ scores in the value added model in column 5 . Their addition attenuates a number of the other coefficients. The coefficients on having a Pakistani or Bangladeshi mother, parental occupational status, being read to and being taught the alphabet are reduced to statistical insignificance. This suggests that while these factors are associated with early achievement at age 3 they are not related to cognitive development between age 3 and 5 .

However, a number of variables remain significant in this model: child's age, being female and having a heavier birth weight are positively associated with the FSP scores. Children with an Indian mother achieve higher FSP scores than white children in this model, as do children with higher parental qualifications. Higher family income is also positively associated with FSP scores, as is experience of formal childcare. On the other side of things, both maternal depression and living in social housing are associated with lower FSP scores. How do the standard deviation differences relate to FSP scores?

Table 1 shows us that for the FSP scores 1 standard deviation is 18.58 so we are able to work out the differences in FSP scores for children with a given set of characteristics. For example, girls, on average, score 3 points higher than boys. Children with Indian mothers score 3 points higher than those with white mothers, all other things being equal.

Children with at least 1 parent with 5 or more A-C passes at GCSE level achieve, on average, 3 more marks than a child with the same characteristics but whose parents do not 
have 5 A-C passes at GCSE. The gap in scores for children with a parent educated to A-level versus $5 \mathrm{~A}-\mathrm{C}$ passes at GCSE is 1 mark, the same as the gap between having a parent with a degree compared to A-levels. Having a family income of $£ 250$ per month higher is associated with an increase in a child's FSP score of 2 points. Having a mother who has had depression reduces a child's FSP score by 1 point and living in social housing produces a score 3 points lower.

As an example, a girl with at least 1 degree educated parent and a £250 per month higher family income will have a 10 point higher FSP score than a girl whose parents do not have $5 \mathrm{~A}-\mathrm{C}$ passes at GCSE level, and who is living in social housing. The initial girl's score will be 13 points higher than a boy in the same situation as the second girl.

For the FSP score, the difference between scoring at the $25^{\text {th }}$ and $50^{\text {th }}$ percentile in the distribution is 14 points, while the gap between the $50^{\text {th }}$ and the $75^{\text {th }}$ percentile is only 11 points (Table 1). Therefore the differences we can attribute to these individual and family characteristics are considerable and are enough to shift a child a considerable way up or down the FSP score distribution.

\section{The bottom 30 percent of achievers}

This analysis has shown the factors most associated with the different cognitive outcomes at age 5. Despite the fact that each test measures slightly different aspects of a child's development at age 5, and one is measured directly from the child's performance the other by the teacher, on the whole, similar characteristics are associated with both outcomes. However, these results only tell us about the factors that are, on average, associated with increased or decreased achievement at age 5. Social scientists and policy makers are also likely to be concerned with the factors related to a child being at the bottom of the achievement distribution. Indeed to ensure that 'no child is left behind' we could argue that policy needs to target children at the bottom, particularly if resources are scarce. 
To allow us to examine this we use regression models to look at the probability a child has of being at the bottom of the achievement distribution at age 5. To do this we use a maximum likelihood probit estimation model $^{7}$ where the outcome variable takes on a value of 1 (if a child is in the bottom 30 per cent of the distribution) or 0 (if they are higher up the distribution).

We consider children to be low achievers if they are amongst the lowest 30 per cent of performers in both the BAS and the FSP assessments at age 5. We combined the two outcomes in this way to capture the children who are in greatest need of help. This group contains 16.8 per cent of children. A further 13.7 are in the bottom 30 per cent on the BAS but not the FSP, and 12.7 per cent are in the bottom 30 per cent on the FSP but not the BAS. Thirty per cent is an arbitrary cutoff-it was chosen to capture the bottom of the distributions but not be so low that the group it defined contained only a very small number of children ${ }^{8}$ causing problems for the robustness and representativeness of our results and raising issues for policy makers trying to accurately identify those most in need of intervention.

The probit model is used to calculate the probability of being in the bottom 30 per cent on both assessments given certain characteristics, controlling for other factors which may affect the relationship. This time the coefficients are interpreted as percentage point differences in the probability of being in the bottom group.

Table 4 shows that all of the child characteristics (column 1) are significantly related to being in the bottom 30 per cent—older children, girls, children with higher birth weight and first born children are less likely to be in the bottom 30 percent of the BAS and FSP.

Of the family characteristics (2), having a Pakistani, Bangladeshi, or black mother are all related to a higher probability of being in the bottom group. Higher parental education and higher family incomes mean that a child has a lower likelihood of being at the bottom of the

\footnotetext{
${ }_{8}^{7}$ We also ran this analysis using a logit model, which produced very similar results.

${ }^{8}$ As a robustness check we also ran the analyses using different cut-off rates -15 and 20 per cent and found a similar pattern of results.
} 
distribution. Living in social housing increases the likelihood of being amongst the lowest achievers.

In the parental choice model (3), children who received formal childcare, are read to every day and are taught the alphabet every day are less likely to be in the bottom group. Children who watch more than three hours of television per day are more likely to be in the bottom group.

In the full model (4), a number of the coefficients are reduced to statistical insignificance. Being first born, having a black mother, and watching 3 or more hours of television per day are no longer related to the probability of being at the bottom of the distribution at age 5 .

Adding the variables which measure whether a child was in the bottom of the distribution on Bracken and BAS at age 3 and in the top of the distribution of problem behaviour at age 3 (column 5) additionally reduces a number of variables to statistical non-significance. Mother's ethnicity no longer accounts for differences in the probability of being in the bottom 30 per cent at age 5 for any ethnic group, nor does experience of formal childcare. However, a number of variables remain significant: girls are around 3 percentage points less likely to be in the bottom 30 per cent; a $1 \mathrm{~kg}$ heavier baby 2 percentage points, and a 3 months older child 1.5 percentage points less likely to be amongst the lowest achievers.

Children with more educated parents are between 2 and 4 percentage points less likely to be in the bottom 30 percent while children with $£ 100$ per month higher family incomes are 2 percentage points less likely to be amongst the lowest achievers. Reading to, and teaching a child the alphabet every day are both associated with a 2 percentage point lower probability of a child being at the bottom of the distribution. However, living in social housing increases the probability of being at the bottom by nearly 5 percentage points.

Being in the bottom of the distribution of Bracken and BAS scores at age 3 are both statistically significantly related to being in the bottom 30 per cent of the BAS and the FSP distributions at age 5 (by 10 and 9 percentages points respectively). But children with the most 
problem behavior at age 3 are no more or less likely to be amongst the lowest achievers at age 5 than other children.

\section{Discussion}

This paper has identified the individual and family factors associated with achievement in both survey-administered tests and teacher-assessed achievement at age 5. It has also highlighted the factors related to the probability of being amongst the poorest 30 percent of performers in these tests at age 5 .

There are a number of factors which are associated with both analyses presented in this paper: younger children, those with lower birth weight, lower parental qualifications, lower income and living in social housing will, on average, have lower BAS and FSP scores at age 5 and have an increased probability of being in the bottom 30 per cent of achievers in these tests. This is also true of children who had lower cognitive scores at age 3 . Policies aimed at these factors therefore could affect both the performance at age 5 in general and target those at the bottom of the distribution. Indeed, the differences in achievement at age 5 , as identified in this paper, are shown to have considerable influence on where a child is located in the achievement distribution. Our conservative estimates of differences in scores produced by variations in some of these background characteristics are enough to shift a child a considerable way up, or down, the distribution. Some of these factors identified highlight exactly where policy makers could target initiatives if they want to affect children's cognitive ability - improving parental education and increasing income for example. These results support initiatives aimed at adult education and ensuring the minimum wage is adequate for low earners. Other factors cannot be changed through policy efforts (e.g., a child's age or gender) but they can help identify which children would benefit most from intervention.

Those interested in raising average cognitive achievement but less concerned with those at the bottom of the distribution could additionally target children with more problem behavior at 
age 3 , who on average, have lower scores in both cognitive tests at age 5 . However, being amongst the worst behaved at age 3 is not related to the probability of being amongst the lowest 30 percent of achievers at age 5. The ethnicity of a mother also has mixed relationships with children's performance at age 5. For BAS, having a Pakistani or Bangladeshi mother or a mother of mixed ethnicity will mean that, on average, a child will have a lower score than a child with a white mother. However, there is no significant difference in FSP scores or the probability of being amongst the lowest achievers for these children or for children with any non-white mother. In fact for the FSP score children with Indian mothers have higher scores, on average, than children with white mothers. Female children have higher FSP scores, on average, than boys and are less likely to be amongst the lowest achievers. However, there is no significant gender gap in the BAS scores once previous ability is controlled for.

Whilst interest in parenting is high on the government agenda, reflected in a range of parenting programmes in initiatives such as SureStart, our results show parental decision factors were not strongly related to outcome in the full models, though reading and teaching the alphabet to children were related to a lower probability of being at the bottom of the distribution. In the OLS regressions, the time parents spent reading and teaching the alphabet to their children was significantly related to outcomes in the full model but not in the value-added model. This suggests that parents' reading to and teaching a child the alphabet is related to a child's cognitive ability, but not necessarily to a change in academic performance between ages 3 and 5.

In addition, these results show previous ability, measured at age 3 , is consistently associated with outcomes at 5 , which supports a call for early intervention. However, the findings also show that not all children who perform badly at 3 also perform badly at 5 and vice versa. Moreover, not all children who perform badly in one area also perform badly in others. Intervention therefore needs to follow children as they grow up and ensure that interventions do 
not label or stigmatise young children who may escape low performance anyway, nor miss children who start well but fall behind later in the education system. 


\section{Acknowledgments}

The authors would like to thank Heather Joshi, participants at the ESF conference in Sweden in 2008 and members of the National Equality Panel for helpful comments on an earlier draft of this paper. Thanks too to the anonymous referees and the Editor Janne Jonsson for suggestions which improved this paper. 


\section{References}

Alexander, K. L., Entwisle, D. R., Blyth, D. A., McAdoo, H. P. (1998). Achievement in the first 2 years of school: patterns and processes. Monographs of the Society for Research in Child Development, 53(2), i-157.

Biedinger, N. (2010). Early ethnic inequality: the influence of social background and parental involvement on preschool children's cognitive ability. Child Indicators Research.

Blanden, J., and Gregg, P. (2004). Family income and educational attainment: A review of approaches and evidence for Britain. Oxford Review of Economic Policy, Special Issue on Education, 20, 245-263.

Blanden, J., Gregg, P., and Machin, S. (2005). Educational Inequality and Intergenerational Mobility, in S. Machin and A. Vignoles (eds.) What's the Good of Education? The Economics of Education in the UK, Princeton University Press.

Blanden, J., Gregg, P., and Macmillan, L. (2007). Accounting for intergenerational persistence. Economic Journal, 117(519). C43-C60.

Blanden, J., and Machin, S. (2007). Recent changes in intergenerational mobility in Britain. Report for the Sutton Trust.

Brooks-Gunn, J., Klebanov, P., and Duncan, G. (1996). Ethnic differences in children's intelligence test scores. Child Development, 67(2), 396-408. 
Caspi, A., Moffitt, T. E., Wright, B. R. E., and Silva, P. A. (1998). Early failure in the labour market: childhood and adolescent predictors of unemployment in the transition to adulthood. American Sociological Review, 63, 424-451.

Duncan, G. J., Dowsett, C. J., Claessens, A., Magnuson, K., and Huston, A. C. (2007). School readiness and later achievement. Developmental Psychology, 43(6), 1428-1446.

Elliott, C. D. (1996). The British Ability Scales II. Windsor, Berkshire: NFER Nelson Publishing Company.

Ermisch, J. (2008). Origins of social immobility and inequality: parenting and early child development. National Institute Economic Review, 205, 62-72.

Feinstein, L. (2003). Inequality in the early cognitive development of British children in the 1970 cohort. Economica, 70(277), 73-98.

Feinstein, L., and Bynner, J. (2004). The importance of cognitive development in middle childhood for adulthood socioeconomic status, mental health, and problem behavior. Child Development, 75(5), 1329-1339.

Feinstein, L., and Duckworth, K. (2006). Development in the early years: its importance for school performance and adult outcomes. WBL Research Report No. 20, London: Centre for Research on the Wider Benefits of Learning.

Fryer Jr., R. G., and Levitt, S. D. (2004). Understanding the Black-White test score gap in the first two years of school. The Review of Economics and Statistics, 86(2), 447-464. 
Fryer Jr., R. G., and Levitt, S. D. (2006). The Black-White test score gap through third grade. American Law and Economics Review, 8(2), 249-281.

George, A., Hansen, K., and Schoon, I. (2007). Cognitive and behavioural outcomes. In K. Hansen and H. Joshi (Eds), Millennium Cohort Study Second Survey: A User's Guide to Initial Findings. CLS.

Goldthorpe , J. (1992). The constant flux: a study of class mobility in industrial societies. Oxford: Clarendon Press.

Goldthorpe, J., and Erikson, R. (2002). Intergenerational inequality: A sociological perspective. Journal of Economic Perspectives, 16(3), 31-44.

Hansen, K., and Hawkes, D. (2009). Childcare and child development. Journal of Social Policy, 38, 211-239.

Hansen, K., Hawkes, D., and Joshi, H. (2009). The timing of motherhood, mothers' employment and child outcomes. Forthcoming in J. Stillwell, Coast, E., and Kneale, D. (eds.) Fertility, Living Arrangements, Care and Mobility. Amsterdam, Springer.

Hill, V. (2005). Through the past darkly: A review of the British Ability Scales Second Edition. Child and Adolescent Mental Health, 10, 87-98.

Linver, M. R., Brooks-Gunn, J., and Kohen, D. E. (2002). Family processes as pathways from income to young children's development. Developmental Psychology, 38(5), 719-734. 
McLoyd, V. C. (1998). Socioeconomic disadvantage and child development. American Psychologist, 53(2), 185-204.

Plewis, I. (2007). The Millennium Cohort Study: technical report on sampling. Centre for Longitudinal Studies, Institute of Education, University of London.

Schoon, I., Bynner, J., Joshi, H., Parsons, S., Wiggins, R. D., and Sacker, A. (2002). The influence of context, timing, and duration of risk experiences for the passage from childhood to midadulthood. Child Development, 73(5), 1486-1504. 
Table 1. Age 5 outcomes.

\begin{tabular}{|l|l|l|l|l|l|l|l|}
\hline & Obs & Mean & $\begin{array}{l}\text { Standard } \\
\text { Deviation }\end{array}$ & Min - Max & $\begin{array}{l}\text { 25th } \\
\text { Percentile }\end{array}$ & $\begin{array}{l}50 \text { th } \\
\text { Percentile }\end{array}$ & $\begin{array}{l}\text { 75th } \\
\text { Percentile }\end{array}$ \\
\hline Age 5 & & & & & & & \\
\hline BAS Overall Score & 7,887 & 101.45 & 14.08 & $\begin{array}{l}23.8- \\
156.6\end{array}$ & 93.4 & 102.8 & 110.7 \\
\hline Foundation Stage Profile & 7,155 & 86.84 & 18.58 & $0-117$ & 76 & 90 & 101 \\
\hline Age 3 & & & & & & & \\
\hline Bracken School Readiness & 7,212 & 103.93 & 16.47 & $56-148$ & 93 & 105 & 116 \\
\hline BAS Naming Vocabulary & 7,612 & 48.89 & 11.64 & $20-80$ & 41 & 49 & 56 \\
\hline
\end{tabular}


Table 2. OLS regression of overall British Ability Scale score at age 5 on child, family, and parental decision factors.

\begin{tabular}{|c|c|c|c|c|c|}
\hline & (1) & (2) & (3) & (4) & (5) \\
\hline Independent variables & $\begin{array}{c}\text { Child } \\
\begin{array}{c}\text { Characteristics } \\
\text { Model }\end{array} \\
\end{array}$ & Family Model & $\begin{array}{c}\text { Parental Decisions } \\
\text { Model }\end{array}$ & Full Model & Value-Added Model \\
\hline \multicolumn{6}{|l|}{ Child Variables } \\
\hline Child's age in months & $0.034(0.003)^{\star * *}$ & & & $0.033(0.002)^{\star * *}$ & $0.033(0.002)^{* * *}$ \\
\hline Child gender female & $0.164(0.025)^{\star * *}$ & & & $0.144(0.023)^{\star * \star}$ & $0.021(0.020)$ \\
\hline Cohort child birth weight in kg & $0.224(0.022)^{\star * *}$ & & & $0.121(0.018)^{\star \star \star}$ & $0.063(0.018)^{\star \star *}$ \\
\hline \multicolumn{6}{|l|}{ Family Variables } \\
\hline Mothers' ethnicity is mixed & & $-0.343(0.109)^{\star * *}$ & & $-0.332(0.107)^{\star * *}$ & $-0.213(0.112)^{*}$ \\
\hline Mothers' ethnicity is Indian & & $-0.256(0.071)^{* * *}$ & & $-0.190(0.071)^{\star \star \star}$ & $-0.058(0.084)$ \\
\hline $\begin{array}{l}\text { Mothers' ethnicity is } \\
\text { Bangladeshi/Pakistani }\end{array}$ & & $-0.690(0.057)^{\star * *}$ & & $-0.619(0.057)^{\star * *}$ & $-0.193(0.071)^{\star * *}$ \\
\hline Mothers' ethnicity is black & & $-0.363(0.068)^{* * *}$ & & $-0.317(0.068)^{\star * \star}$ & $-0.073(0.071)$ \\
\hline $\begin{array}{l}\text { Highest parental qualification is } \\
\text { GCSE A to C }\end{array}$ & & $0.272(0.043)^{\star * *}$ & & $0.246(0.043)^{\star \star *}$ & $0.121(0.041)^{\star * *}$ \\
\hline $\begin{array}{l}\text { Highest parental qualification is } \\
\text { A-levels }\end{array}$ & & $0.361(0.049)^{* * *}$ & & $0.316(0.049)^{* * *}$ & $0.142(0.046)^{* * *}$ \\
\hline $\begin{array}{l}\text { Highest parental qualification is } \\
\text { degree or higher }\end{array}$ & & $0.508(0.046)^{* * *}$ & & $0.444(0.046)^{* * *}$ & $0.198(0.043)^{* * *}$ \\
\hline $\begin{array}{l}\text { Family income in } £ 100 \text { per } \\
\text { month, average of MCS } 1 \text { and } \\
\text { MCS } 2\end{array}$ & & $0.103(0.011)^{* * *}$ & & $0.091(0.011)^{\star * *}$ & $0.051(0.013)^{* * *}$ \\
\hline $\begin{array}{l}\text { Mother's has had doctor- } \\
\text { diagnosed depression }\end{array}$ & & $-0.044(0.023)^{*}$ & & $-0.039(0.023)^{*}$ & $0.020(0.021)$ \\
\hline Has ever been lone parent & & $-0.016(0.035)$ & & $-0.016(0.034)$ & $0.004(0.033)$ \\
\hline $\begin{array}{l}\text { Highest NSSEC of } \\
\text { mother/father at MCS } 2 \text { is } \\
\text { Professional \& managerial }\end{array}$ & & $0.094(0.029)^{* * *}$ & & $0.084(0.029)^{\star * *}$ & $0.059(0.027)^{\star *}$ \\
\hline Social housing at MCS 2 & & $-0.143(0.034)^{\star \star \star}$ & & $-0.122(0.034)^{\star \star \star}$ & $-0.027(0.035)$ \\
\hline
\end{tabular}




\begin{tabular}{|c|c|c|c|c|c|}
\hline & (1) & (2) & (3) & (4) & (5) \\
\hline Independent variables & $\begin{array}{c}\text { Child } \\
\text { Characteristics } \\
\text { Model }\end{array}$ & Family Model & $\begin{array}{c}\text { Parental Decisions } \\
\text { Model }\end{array}$ & Full Model & Value-Added Model \\
\hline $\begin{array}{l}\text { Cohort child ever received } \\
\text { formal childcare }\end{array}$ & & & $0.269(0.032)^{* * *}$ & $0.070(0.029)^{* *}$ & $-0.006(0.030)$ \\
\hline $\begin{array}{l}\text { Child read to every day at age } \\
3\end{array}$ & & & $0.320(0.028)^{\star * *}$ & $0.147(0.025)^{* * *}$ & $0.030(0.023)$ \\
\hline $\begin{array}{l}\text { Child taught alphabet every day } \\
\text { at age } 3\end{array}$ & & & $0.098(0.028)^{\star * *}$ & $0.117(0.027)^{\star * \star}$ & $0.054(0.029)^{*}$ \\
\hline $\begin{array}{l}\text { Child taught counting every day } \\
\text { at age } 3\end{array}$ & & & $0.007(0.025)$ & $-0.017(0.023)$ & $-0.045(0.022)^{\star *}$ \\
\hline $\begin{array}{l}\text { Child watches TV } 3 \text { or more hrs } \\
\text { per day at age } 3\end{array}$ & & & $-0.178(0.030)^{\star \star \star}$ & $-0.027(0.027)$ & $-0.038(0.028)$ \\
\hline \multicolumn{6}{|l|}{ Added Value Variables } \\
\hline Bracken score at age 3 & & & & & $0.275(0.014)^{\star \star *}$ \\
\hline $\begin{array}{l}\text { Bas Naming Vocabulary score } \\
\text { at age } 3\end{array}$ & & & & & $0.199(0.014)^{* * *}$ \\
\hline Problem Behaviour score at 3 & & & & & $-0.044(0.011)^{\star \star \star}$ \\
\hline Observations & 7887 & 7655 & 7887 & 7655 & 6387 \\
\hline $\mathrm{R}^{2}$ & 0.06 & 0.17 & 0.09 & 0.19 & 0.31 \\
\hline
\end{tabular}

Notes. Standard errors in parentheses. ${ }^{\star} p<.10$, ${ }^{\star \star} p<.05$, ${ }^{\star \star \star} p<.01$ 
Table 3. OLS regression of Foundation Stage Profile score at age 5 on child, family, and parental decision factors.

\begin{tabular}{|c|c|c|c|c|c|}
\hline & $(1)$ & (2) & (3) & (4) & (5) \\
\hline Independent variables & $\begin{array}{c}\text { Child } \\
\begin{array}{c}\text { Characteristics } \\
\text { Model }\end{array} \\
\end{array}$ & Family Model & $\begin{array}{c}\text { Parental Decisions } \\
\text { Model }\end{array}$ & Full Model & Value-Added Model \\
\hline \multicolumn{6}{|l|}{ Child Variables } \\
\hline Child's age in months & $0.069(0.004)^{* * *}$ & & & $0.074(0.003)^{* * *}$ & $0.075(0.003)^{\star * *}$ \\
\hline Child gender female & $0.293(0.023)^{* * *}$ & & & $0.263(0.020)^{* * *}$ & $0.159(0.019)^{* * *}$ \\
\hline Cohort child birth weight in kg & $0.207(0.026)^{* * *}$ & & & $0.112(0.024)^{* * *}$ & $0.056(0.022)^{\star \star *}$ \\
\hline Cohort child is first born & $0.111(0.026)^{* * *}$ & & & $0.021(0.025)$ & $-0.023(0.025)$ \\
\hline \multicolumn{6}{|l|}{ Family Variables } \\
\hline Mothers' ethnicity is mixed & & $-0.137(0.133)$ & & $-0.089(0.116)$ & $0.137(0.110)$ \\
\hline Mothers' ethnicity is Indian & & $-0.109(0.063)^{*}$ & & $-0.023(0.063)$ & $0.159(0.071)^{\star \star}$ \\
\hline $\begin{array}{l}\text { Mothers' ethnicity is } \\
\text { Bangladeshi/Pakistani }\end{array}$ & & $-0.398(0.087)^{\star \star \star}$ & & $-0.291(0.088)^{\star \star \star}$ & $0.098(0.114)$ \\
\hline Mothers' ethnicity is black & & $-0.115(0.096)$ & & $-0.050(0.093)$ & $-0.031(0.106)$ \\
\hline $\begin{array}{l}\text { Highest parental qualification is } \\
\text { GCSE A to C }\end{array}$ & & $0.263(0.038)^{\star * *}$ & & $0.229(0.036)^{\star * *}$ & $0.156(0.038)^{\star \star \star}$ \\
\hline $\begin{array}{l}\text { Highest parental qualification is } \\
\text { A-levels }\end{array}$ & & $0.384(0.043)^{* * *}$ & & $0.327(0.043)^{* * *}$ & $0.201(0.043)^{\star * *}$ \\
\hline $\begin{array}{l}\text { Highest parental qualification is } \\
\text { degree or higher }\end{array}$ & & $0.507(0.040)^{\star * *}$ & & $0.428(0.037)^{* * *}$ & $0.267(0.039)^{* * *}$ \\
\hline $\begin{array}{l}\text { Family income in } £ 100 \text { per } \\
\text { month, average of MCS } 1 \text { and } \\
\text { MCS } 2\end{array}$ & & $0.105(0.010)^{* * *}$ & & $0.091(0.011)^{* * *}$ & $0.044(0.012)^{\star * *}$ \\
\hline $\begin{array}{l}\text { Mother's has had doctor- } \\
\text { diagnosed depression }\end{array}$ & & $-0.104(0.024)^{\star * *}$ & & $-0.103(0.023)^{* * *}$ & $-0.059(0.022)^{* * *}$ \\
\hline Has ever been lone parent & & $-0.063(0.037)^{*}$ & & $-0.055(0.036)$ & $-0.040(0.034)$ \\
\hline $\begin{array}{l}\text { Highest NSSEC of } \\
\text { mother/father at MCS } 2 \text { is } \\
\text { Professional \& managerial }\end{array}$ & & $0.091(0.027)^{\star * *}$ & & $0.075(0.027)^{\star * *}$ & $0.029(0.025)$ \\
\hline Social housing at MCS 2 & & $-0.268(0.035)^{\star \star \star}$ & & $-0.244(0.034)^{* * *}$ & $-0.155(0.034)^{* * *}$ \\
\hline
\end{tabular}




\begin{tabular}{|c|c|c|c|c|c|}
\hline & (1) & (2) & (3) & (4) & (5) \\
\hline Independent variables & $\begin{array}{c}\text { Child } \\
\begin{array}{c}\text { Characteristics } \\
\text { Model }\end{array} \\
\end{array}$ & Family Model & $\begin{array}{c}\text { Parental Decisions } \\
\text { Model }\end{array}$ & Full Model & Value-Added Model \\
\hline $\begin{array}{l}\text { Cohort child ever received } \\
\text { formal childcare }\end{array}$ & & & $0.328(0.038)^{* * *}$ & $0.137(0.034)^{* * *}$ & $0.063(0.035)^{*}$ \\
\hline $\begin{array}{l}\text { Child read to every day at age } \\
3\end{array}$ & & & $0.310(0.027)^{\star * \star}$ & $0.151(0.024)^{\star * *}$ & $0.037(0.023)$ \\
\hline $\begin{array}{l}\text { Child taught alphabet every } \\
\text { day at age } 3\end{array}$ & & & $0.070(0.034)^{* *}$ & $0.066(0.032)^{* *}$ & $-0.001(0.031)$ \\
\hline $\begin{array}{l}\text { Child taught counting every } \\
\text { day at age } 3\end{array}$ & & & $0.049(0.030)$ & $0.041(0.028)$ & $0.023(0.027)$ \\
\hline $\begin{array}{l}\text { Child watches TV } 3 \text { or more } \\
\text { hrs per day at age } 3\end{array}$ & & & $-0.187(0.029)^{\star \star *}$ & $-0.029(0.027)$ & $-0.038(0.029)$ \\
\hline \multicolumn{6}{|l|}{ Added Value Variables } \\
\hline Bracken score at age 3 & & & & & $0.277(0.014)^{\star * *}$ \\
\hline $\begin{array}{l}\text { Bas Naming Vocabulary score } \\
\text { at age } 3\end{array}$ & & & & & $0.120(0.013)^{\star \star \star}$ \\
\hline Problem Behaviour score at 3 & & & & & $-0.066(0.011)^{* * *}$ \\
\hline Observations & 7155 & 6955 & 7155 & 6955 & 5764 \\
\hline $\mathrm{R}^{2}$ & 0.10 & 0.21 & 0.14 & 0.25 & 0.35 \\
\hline
\end{tabular}


Table 4. Probit regression of being in bottom 30 per cent of achievers at age 5 on child, family, and parental decision

factors.

\begin{tabular}{|c|c|c|c|c|c|}
\hline & (1) & (2) & (3) & (4) & (5) \\
\hline Independent variables & $\begin{array}{c}\text { Child } \\
\begin{array}{c}\text { Characteristics } \\
\text { Model }\end{array} \\
\end{array}$ & Family Model & $\begin{array}{c}\text { Parental Decisions } \\
\text { Model }\end{array}$ & Full Model & Value-Added Model \\
\hline \multicolumn{6}{|l|}{ Child Variables } \\
\hline Child's age in months & $-0.007(0.001)^{\star * \star}$ & & & $-0.006(0.001)^{* \star \star}$ & $-0.005(0.001)^{* \star \star}$ \\
\hline Child gender female & $-0.054(0.008)^{\star * *}$ & & & $-0.050(0.007)^{\star * \star}$ & $-0.028(0.007)^{* * *}$ \\
\hline Cohort child birth weight in kg & $-0.059(0.008)^{\star * *}$ & & & $-0.032(0.007)^{\star \star \star}$ & $-0.020(0.006)^{\star \star \star}$ \\
\hline Cohort child is first born & $-0.029(0.008)^{\star * *}$ & & & $-0.006(0.007)$ & $-0.002(0.007)$ \\
\hline \multicolumn{6}{|l|}{ Family Variables } \\
\hline Mothers' ethnicity is mixed & & $0.031(0.037)$ & & $0.024(0.035)$ & $0.006(0.027)$ \\
\hline Mothers' ethnicity is Indian & & $0.033(0.025)$ & & $0.008(0.024)$ & $-0.022(0.016)$ \\
\hline $\begin{array}{l}\text { Mothers' ethnicity is } \\
\text { Bangladeshi/Pakistani }\end{array}$ & & $0.150(0.022)^{\star \star \star}$ & & $0.112(0.021)^{\star \star *}$ & $0.016(0.019)$ \\
\hline Mothers' ethnicity is black & & $0.037(0.021)^{\star}$ & & $0.019(0.019)$ & $-0.014(0.017)$ \\
\hline $\begin{array}{l}\text { Highest parental qualification is } \\
\text { GCSE A to C }\end{array}$ & & $-0.045(0.008)^{\star \star \star}$ & & $-0.040(0.008)^{\star \star \star}$ & $-0.021(0.008)^{\star \star \star}$ \\
\hline $\begin{array}{l}\text { Highest parental qualification is } \\
\text { A-levels }\end{array}$ & & $-0.050(0.009)^{\star \star \star}$ & & $-0.041(0.009)^{\star \star \star}$ & $-0.022(0.009)^{\star *}$ \\
\hline $\begin{array}{l}\text { Highest parental qualification is } \\
\text { degree or higher }\end{array}$ & & $-0.095(0.012)^{\star * *}$ & & $-0.077(0.012)^{\star \star *}$ & $-0.041(0.011)^{\star * *}$ \\
\hline $\begin{array}{l}\text { Family income in } £ 100 \text { per } \\
\text { month, average of MCS } 1 \text { and } \\
\text { MCS } 2\end{array}$ & & $-0.031(0.006)^{* * *}$ & & $-0.028(0.006)^{* * *}$ & $-0.019(0.005)^{\star \star *}$ \\
\hline $\begin{array}{l}\text { Mother's has had doctor- } \\
\text { diagnosed depression }\end{array}$ & & $0.011(0.008)$ & & $0.010(0.008)$ & $0.004(0.007)$ \\
\hline Has ever been lone parent & & $-0.009(0.009)$ & & $-0.011(0.009)$ & $-0.005(0.009)$ \\
\hline $\begin{array}{l}\text { Highest NSSEC of } \\
\text { mother/father at MCS } 2 \text { is } \\
\text { Professional \& managerial }\end{array}$ & & $-0.018(0.011)$ & & $-0.015(0.011)$ & $-0.010(0.010)$ \\
\hline Social housing at MCS 2 & & $0.063(0.012)^{\star \star \star}$ & & $0.056(0.011)^{\star \star \star}$ & $0.047(0.012)^{\star \star \star}$ \\
\hline Parental Decisions Variables & & & & & \\
\hline
\end{tabular}




\begin{tabular}{|c|c|c|c|c|c|}
\hline & (1) & (2) & (3) & (4) & (5) \\
\hline Independent variables & $\begin{array}{c}\text { Child } \\
\begin{array}{c}\text { Characteristics } \\
\text { Model }\end{array}\end{array}$ & Family Model & $\begin{array}{c}\text { Parental Decisions } \\
\text { Model }\end{array}$ & Full Model & Value-Added Model \\
\hline $\begin{array}{l}\text { Cohort child ever received } \\
\text { formal childcare }\end{array}$ & & & $-0.081(0.011)^{\star \star *}$ & $-0.025(0.008)^{\star * *}$ & $-0.005(0.008)$ \\
\hline $\begin{array}{l}\text { Child read to every day at age } \\
3\end{array}$ & & & $-0.078(0.008)^{\star \star \star}$ & $-0.034(0.007)^{\star \star \star}$ & $-0.016(0.007)^{\star *}$ \\
\hline $\begin{array}{l}\text { Child taught alphabet every } \\
\text { day at age } 3\end{array}$ & & & $-0.020(0.009)^{* *}$ & $-0.021(0.008)^{\star *}$ & $-0.020(0.008)^{\star *}$ \\
\hline $\begin{array}{l}\text { Child taught counting every } \\
\text { day at age } 3\end{array}$ & & & $-0.010(0.009)$ & $-0.002(0.008)$ & $0.001(0.007)$ \\
\hline $\begin{array}{l}\text { Child watches TV } 3 \text { or more } \\
\text { hrs per day at age } 3\end{array}$ & & & $0.045(0.011)^{\star * *}$ & $0.003(0.008)$ & $0.006(0.009)$ \\
\hline \multicolumn{6}{|l|}{ Added Value Variables } \\
\hline Bracken score at age 3 & & & & & $0.099(0.015)^{\star * \star}$ \\
\hline $\begin{array}{l}\text { Bas Naming Vocabulary score } \\
\text { at age } 3\end{array}$ & & & & & $0.087(0.012)^{* * *}$ \\
\hline Problem Behaviour score at 3 & & & & & $-0.010(0.009)$ \\
\hline Observations & 7701 & 7487 & 7701 & 7478 & 6268 \\
\hline $\mathrm{F}$ & 32.232 & 35.646 & 39.714 & 28.374 & 32.208 \\
\hline $\mathrm{p}$ & 0.000 & 0.000 & 0.000 & 0.000 & 0.000 \\
\hline
\end{tabular}


Appendices 
Appendix 1. Descriptives for Continuous Independent Variables.

\begin{tabular}{|l|l|l|l|l|l|l|l|}
\hline & Obs & Mean & $\begin{array}{l}\text { Standard } \\
\text { Deviation }\end{array}$ & Min - Max & $\begin{array}{l}\text { 25th } \\
\text { Percentile }\end{array}$ & $\begin{array}{l}\text { 50th } \\
\text { Percentile }\end{array}$ & $\begin{array}{l}\text { 75th } \\
\text { Percentile }\end{array}$ \\
\hline Age in months at MCS 3 & 8,129 & 57.57 & 4.84 & $48-72$ & 60 & 60 & 60 \\
\hline Age in months at FSP & 8,131 & 63.58 & 3.48 & $58-69$ & 61 & 64 & 67 \\
\hline Birthweight in kilos & 8,114 & 3.37 & 0.59 & $0.4-5.9$ & 3.1 & 3.4 & 3.7 \\
\hline $\begin{array}{l}\text { Family income, average of } \\
\text { MCS 1 and MCS 2 }\end{array}$ & 7,478 & 1.94 & 1.26 & $0.1-6.7$ & 1.0 & 1.7 & 2.4 \\
\hline Bracken score at MCS 2 & 7,212 & 105.94 & 15.76 & $56-148$ & 96 & 107 & 117 \\
\hline $\begin{array}{l}\text { BAS Naming Vocab at MCS } \\
2\end{array}$ & 7,612 & 50.53 & 10.90 & $20-80$ & 43 & 49 & 58 \\
\hline
\end{tabular}

Notes. Means, standard deviations, and centiles are weighted with weight1. Obs are the unweighted number of observations. 
Appendix 2. Descriptives for Discrete Independent Variables.

\begin{tabular}{|c|c|c|}
\hline & Obs & $\%$ \\
\hline \multicolumn{3}{|l|}{ Child gender } \\
\hline Female & 4,004 & 49.12 \\
\hline Male & 4,127 & 50.88 \\
\hline \multicolumn{3}{|l|}{ Child is first born } \\
\hline No & 4,105 & 50.06 \\
\hline Yes & 3,918 & 49.94 \\
\hline \multicolumn{3}{|l|}{ Mother's ethnicity } \\
\hline White & 6,457 & 89.74 \\
\hline Mixed & 92 & 0.84 \\
\hline Indian & 306 & 2.05 \\
\hline Pakistani or Bangladeshi & 725 & 3.73 \\
\hline Black & 349 & 2.34 \\
\hline \multicolumn{3}{|l|}{ Highest parental qualification, MCS 2} \\
\hline No qualifications or NVQ 1 & 1,297 & 11.50 \\
\hline NVQ 2 & 2,019 & 24.80 \\
\hline NVQ 3 & 1,451 & 18.60 \\
\hline NVQ 4 or 5 & 3,121 & 45.11 \\
\hline \multicolumn{3}{|c|}{$\begin{array}{l}\text { Mother's has had doctor-diagnosed depression at } \\
\text { MCS } 1 \text { or MCS } 2\end{array}$} \\
\hline No & 5,443 & 66.48 \\
\hline Yes & 2,683 & 33.52 \\
\hline \multicolumn{3}{|c|}{ Mother has been lone parent up to MCS 2} \\
\hline No & 6,913 & 86.88 \\
\hline Yes & 1,218 & 13.12 \\
\hline \multicolumn{3}{|c|}{ Highest NSSEC of mother/father at MCS 2} \\
\hline Not professional or managerial & 6,523 & 76.98 \\
\hline Professional or managerial & 1,608 & 23.02 \\
\hline \multicolumn{3}{|l|}{ Housing tenure at MCS 2} \\
\hline Not social housing & 6,205 & 80.57 \\
\hline
\end{tabular}




\begin{tabular}{|l|c|c|}
\hline & Obs & $\%$ \\
\hline Social housing & 1,925 & 19.43 \\
\hline $\begin{array}{l}\text { Cohort child ever received formal childcare up to } \\
\text { MCS 2 }\end{array}$ & & \\
\hline No & 1,935 & 19.13 \\
\hline Yes & 6,196 & 80.87 \\
\hline Child read to every day at MCS 2 & & \\
\hline No & 3,442 & 37.42 \\
\hline Yes & 4,689 & 62.58 \\
\hline Child taught alphabet every day at MCS 2 & & \\
\hline No & 5,082 & 75.91 \\
\hline Yes & 1,672 & 24.09 \\
\hline Child taught counting every day at MCS 2 & & \\
\hline No & 3,901 & 48.71 \\
\hline Yes & 3,927 & 51.29 \\
\hline Child watches TV 3 or more hrs per day at MCS 2 & & \\
\hline No & 6,667 & 84.31 \\
\hline Yes & 1,464 & 15.69 \\
\hline
\end{tabular}

Notes. Percentages are weighted with weight1. Obs are the unweighted number of observations. 